\title{
Ractopamina, cromo-metionina e suas combinações como aditivos modificadores do metabolismo de suínos em crescimento e terminação
}

\author{
Vivian Vezzoni de Almeida ${ }^{1}$, Bernardo Berenchtein ${ }^{2}$, Leandro Batista Costa ${ }^{2}$, Marcos Livio \\ Panhoza Tse ${ }^{2}$, Débora Barbosa Braz ${ }^{2}$, Valdomiro Shigueru Miyada ${ }^{3}$
}

1 Programa de Pós-graduação em Ciência Animal e Pastagens - Departamento de Zootecnia-ESALQ/USP. Av. Pádua Dias nº 11, Caixa Postal 9, Bairro Agronomia - CEP: 13418-900, Piracicaba, SP - Bolsista Capes.

2 Programa de Pós-graduação em Zootecnia - Departamento de Zootecnia - ESALQ/USP, Piracicaba, SP.

${ }^{3}$ Departamento de Zootecnia - ESALQ/USP, Piracicaba, SP.

RESUMO - Objetivou-se neste estudo avaliar o efeito da adição de ractopamina, cromo-metionina e suas combinações em dietas para suínos em crescimento e terminação sobre o desempenho, as características de carcaça e a qualidade da carne. Sessenta e quatro suínos da linhagem Topigs, com peso inicial de $26,56 \pm 3,11 \mathrm{~kg}$, foram distribuídos em delineamento experimental de blocos casualizados em esquema fatorial $2 \times 2$, com dois níveis de ractopamina ( 0 e 5 ppm) e dois níveis de cromo-metionina ( 0 e $400 \mathrm{ppb}$ ), totalizando quatro dietas com oito repetições (blocos) por dieta. Em cada uma das três fases, crescimento 1 (de $26,56 \mathrm{~kg}$ aos $50,51 \mathrm{~kg}$ ), crescimento 2 (de $50,51 \mathrm{~kg}$ aos $70,32 \mathrm{~kg}$ ) e terminação (de $70,32 \mathrm{~kg}$ aos $114,80 \mathrm{~kg}$ ), os animais receberam rações fareladas e água à vontade. Ao atingirem o peso vivo de 114,80 $\pm 4,98 \mathrm{~kg}$, os animais foram abatidos e as carcaças avaliadas quanto ao rendimento de carcaça fria, ao comprimento de carcaça, à espessura de toucinho, à área de olho-de-lombo e à relação gordura:carne. Amostras do músculo longissimus dorsi foram retiradas para mensurações de cor, pH final e perda de peso por gotejamento. A suplementação de ractopamina melhorou a conversão alimentar, o rendimento de carcaça fria, a área de olho-de-lombo, a relação gordura:carne e a perda de peso por gotejamento e reduziu os teores de vermelho e amarelo da carne. O cromo-metionina, embora tenha ocasionado redução no consumo diário de ração, não altera as características de desempenho e de carcaça nem a qualidade da carne dos suínos. A suplementação de ractopamina associada a cromo-metionina não afeta o desempenho nem as características de carcaça e qualidade da carne dos animais.

Palavras-chave: agonista beta-adrenérgico, carcaça, carne, desempenho, nutrição

\section{Ractopamine, chromium-methionine and their combinations as metabolism modifier feed additives of growing and finishing pigs}

\begin{abstract}
The purpose of this study was to evaluate the effect of ractopamine and chromium-methionine additions and their combinations in diets for growing and finishing swines on performance, carcass traits and meat quality. Sixty-four Topigs line swines at $26.56 \pm 3.11 \mathrm{~kg}$ initial body weight were distributed in a randomized block experimental design in a $2 \times 2$ factorial scheme with two levels of ractopamine $(0$ and $5 \mathrm{ppm})$ and two levels of chromium-methionine $(0$ and $400 \mathrm{ppb}$ ), totaling four diets with eight replications (blocks) per diet. In each one of the three following phases, growing 1 (from $26.56 \mathrm{~kg}$ to $50.51 \mathrm{~kg}$ ), growing 2 (from $50.51 \mathrm{~kg}$ to $70.32 \mathrm{~kg}$ ) and finishing (from $70.32 \mathrm{~kg}$ to $114.80 \mathrm{~kg}$ ), meal rations and water were given ad libitum to animals. When pigs reached $114.80 \pm 4.98 \mathrm{~kg}$ body weight, they were slaughtered and carcasses were evaluated regarded to cold carcass yield, carcass length, backfat thickness, loin eye area and fat:meat ratio Samples of longissimus dorsi muscle were taken to measure colour, final pH and drip loss. Supplementation of ractopamine improved feed conversion, cold carcass yield, loin eye area, fat:meat ratio and drip loss, and it reduced redness and yellowness components of meat. Although chromium-methionine decreased daily feed intake, it does not affect the performance and carcass traits neither meat quality of swines. Supplementation of ractopamine combined to chromium-methionine do not affect carcass traits and meat quality of animals.
\end{abstract}

Key Words: beta-adrenergic agonist, carcass, meat, nutrition, performance

\section{Introdução}

Dentro do setor de produção de proteína animal, a suinocultura cada vez mais se solidifica como uma atividade de extrema valia no cenário nacional. No entanto, tradicionalmente, o Brasil não é um grande consumidor de carne suína. Atribui-se ao baixo consumo nacional a formação de uma imagem negativa associada à carne suína, 
resultante de uma série de mitos relacionados a possíveis efeitos deletérios da carne suína à saúde humana (Schlindwein \& Kassouf, 2006). Nesse sentido, a gordura tem sido um produto pouco valorizado, sendo o foco, na atualidade, a produção de animais mais eficientes e com menor relação gordura:carne.

Diante de pressões dos consumidores modernos, relativas a mudanças nas preferências e nos hábitos alimentares, ou seja, maiores quantidades de cortes nobres, têm-se adotado novas tecnologias na área de nutrição, dentre as quais se destacam os aditivos modificadores do metabolismo animal, como a ractopamina e o cromo na forma orgânica. As ações mediadas pela ractopamina, um agonista beta-adrenérgico, ocorrem no interior da membrana celular após a estimulação dos receptores do tipo beta, aumentando a produção de monofosfato cíclico de adenosina (AMPc) (McGraw \& Liggett, 2005). Todavia, a participação do cromo no metabolismo resume-se ao aumento da sensibilidade à insulina, por meio da ligação de quatro átomos de cromo a uma proteína intracelular específica denominada apocromodulina (Vincent, 2000). Tais aditivos promovem respostas celulares que incluem aumento da deposição proteica e diminuição da quantidade de gordura na carcaça (Lien et al., 2001; See et al., 2004).

Destacam-se como os principais atributos da qualidade da carne suína a aparência, a textura, a suculência, o sabor e o valor nutricional (Marchi, 2001). Há relatos mostrando que a ractopamina não influencia a coloração da carne, o pH mensurado 24 horas post mortem e a perda de peso por gotejamento (Bridi et al., 2006). Porém, alterações na qualidade da carne, principalmente no que concernem aos parâmetros de cor, foram detectadas (Uttaro et al., 1993). A qualidade da carne suína não é afetada pela inclusão de cromo na forma de picolinato de cromo nas dietas de suínos em crescimento e terminação (Boleman et al., 1995).

Apesar de comprovada a ação da ractopamina, existem poucas informações sobre o uso do cromo como potencial modificador de carcaça suína. Além disso, pouco se sabe sobre os efeitos da suplementação associada de ambos aditivos em dietas para suínos. Assim, objetivou-se com este trabalho avaliar os efeitos da ractopamina, do cromometionina e de suas combinações sobre o desempenho, as características de carcaça e a qualidade da carne de suínos em crescimento e terminação.

\section{Material e Métodos}

O experimento foi conduzido no Setor de Suinocultura do Departamento de Zootecnia, da Escola Superior de Agricultura "Luiz de Queiroz", da Universidade de São
Paulo, Piracicaba, São Paulo. A instalação de crescimento e terminação, onde os animais foram alojados, é dotada de cobertura de telhas de barro, possuindo 32 baias com divisórias metálicas vazadas, dispostas em duas faixas de 16 baias. Cada baia possui uma área de $3,48 \mathrm{~m}^{2}(1,20 \mathrm{~m} \times$ 2,90 m), sendo provida de comedouro semiautomático e bebedouro tipo chupeta. A área encontrada imediatamente abaixo do bebedouro é de piso ripado e o restante, de concreto compacto, correspondente à área adjacente ao comedouro.

Foram utilizados 64 animais da linhagem Topigs, sendo 32 machos castrados e 32 fêmeas, com peso médio inicial de $26,56 \pm 3,11 \mathrm{~kg}$ e 68 dias de idade, distribuídos em um delineamento experimental de blocos casualizados completos em esquema fatorial $2 \times 2$, sendo dois níveis de ractopamina ( 0 e $5 \mathrm{ppm}$ ) e dois níveis de cromo-metionina (0 e $400 \mathrm{ppb}$ ), totalizando quatro dietas com oito repetições por dieta e dois animais por unidade experimental (um macho castrado e uma fêmea). Ao chegarem às instalações experimentais, os animais foram pesados e distribuídos nas baias de acordo com o peso inicial e o sexo.

As dietas experimentais foram: controle: dieta basal constituída de milho e farelo de soja; cromo-metionina: dieta basal com $400 \mathrm{ppb}$ de cromo-metionina na fase dos $26,56 \mathrm{~kg}$ aos $114,80 \mathrm{~kg}$; ractopamina: dieta basal com $5 \mathrm{ppm}$ de ractopamina dos $70,32 \mathrm{~kg}$ aos $114,80 \mathrm{~kg}$; ractopamina + cromo-metionina: dieta basal com inclusão de 400 ppb de cromo-metionina dos $26,56 \mathrm{~kg}$ aos $114,80 \mathrm{~kg}$ de PV e $5 \mathrm{ppm}$ de ractopamina dos 70,32 $\mathrm{kg}$ aos $114,80 \mathrm{~kg}$ de PV.

O período experimental médio foi de 91 dias, dividido em três fases, de acordo com o peso vivo dos animais, quando foi realizada a mudança das rações: crescimento 1: dos $26,56 \mathrm{~kg}$ aos $50,51 \mathrm{~kg}$; crescimento $2: \operatorname{dos} 50,51 \mathrm{~kg}$ aos $70,32 \mathrm{~kg}$; e terminação: dos $70,32 \mathrm{~kg}$ aos $114,80 \mathrm{~kg}$. Os animais receberam ração farelada e água à vontade durante todo o experimento.

As dietas experimentais (Tabelas 1), à base de milho e farelo de soja, suplementadas com vitaminas, minerais e aminoácidos, foram formuladas utilizando-se o conceito de proteína ideal, e os níveis de exigência nutricional foram estabelecidos segundo recomendações comerciais. As dietas experimentais da fase de terminação foram formuladas para conterem $0,90 \%$ de lisina digestível. O nível de $0,90 \%$ de lisina digestível foi estabelecido, uma vez que suínos suplementados com ractopamina devem consumir, aproximadamente, $30 \%$ a mais de sua exigência de lisina, conforme recomendado por Mitchell et al. (1991).

As variáveis de desempenho (consumo diário de ração, ganho diário de peso e conversão alimentar) foram calculadas a partir das pesagens de rações efetuadas 


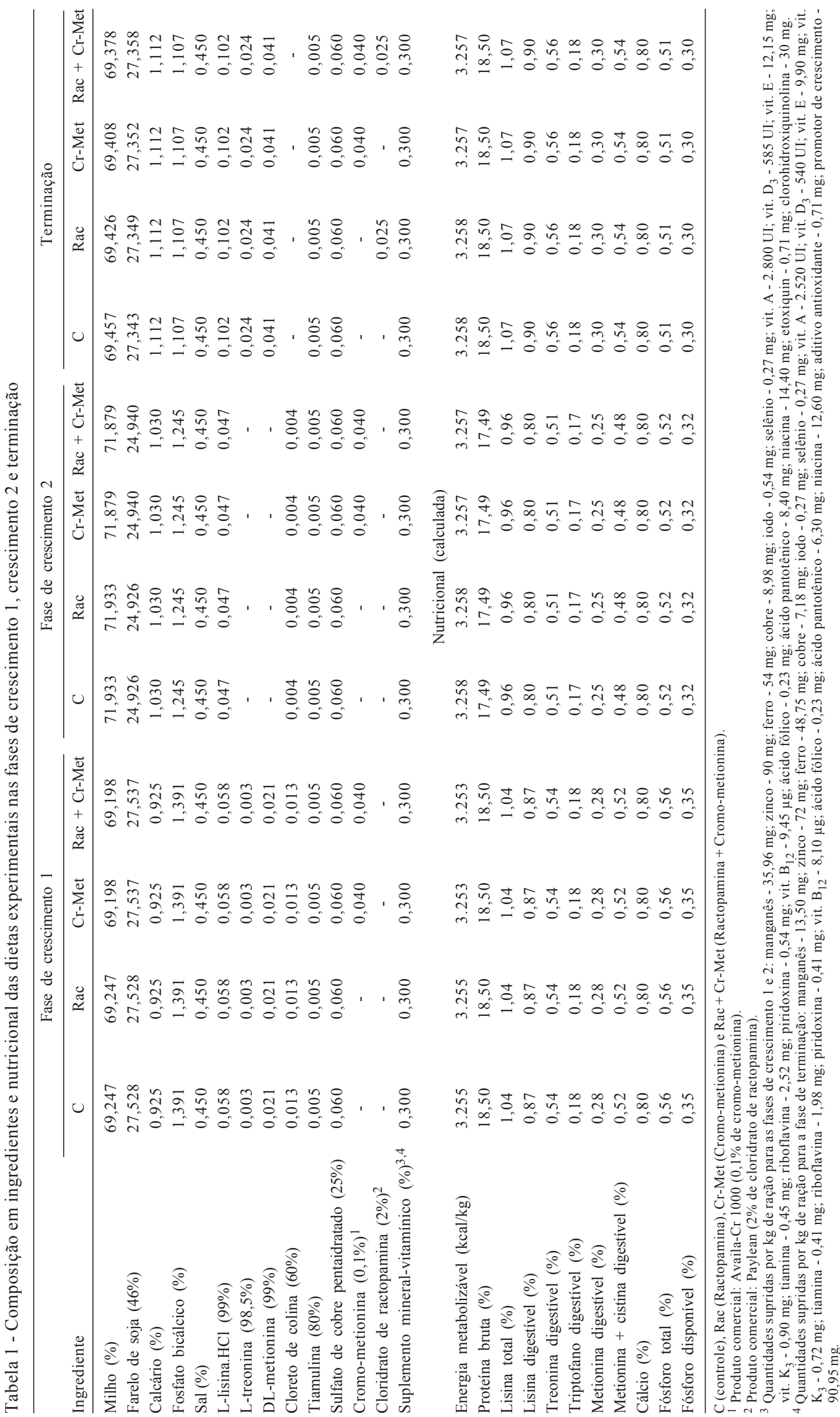

R. Bras. Zootec., v.39, n.9, p.1969-1977, 2010 
periodicamente, das quantificações das sobras de rações realizadas diariamente e de pesagens individuais dos animais no início e no final de cada fase.

Quando atingiram o peso vivo médio de 114,80 $44,98 \mathrm{~kg}$, os animais foram submetidos a jejum sólido de 24 horas e, posteriormente, encaminhados ao Frigorífico Angelelli Ltda., localizado no município de Piracicaba, SP, onde foram abatidos. Após a retirada das vísceras, as carcaças foram seccionadas no sentido longitudinal, pesadas e colocadas em câmara fria a $4{ }^{\circ} \mathrm{C}$ por 24 horas, quando, então, foram avaliadas. Na meia-carcaça esquerda de cada animal foram realizadas as seguintes medidas: rendimento de carcaça fria, comprimento da carcaça, espessura média de toucinho (resultante de três medições realizadas na altura das primeira e última vértebras torácicas e última vértebra lombar), área de olho-de-lombo e relação gordura:carne, conforme descritas no Método Brasileiro de Classificação de Carcaças (ABCS, 1973).

Após 24 horas post mortem, foram retiradas amostras do músculo longissimus dorsi da meia carcaça esquerda de cada animal para realização das análises física (cor e perda de peso por gotejamento) e química ( $\mathrm{pH}$ final) da carne no Laboratório de Qualidade e Processamento de Carnes, do Departamento de Agroindústria, Alimentos e Nutrição, da Escola Superior de Agricultura "Luiz de Queiroz", da Universidade de São Paulo, Piracicaba, SP.

A cor instrumental foi mensurada sobre a superfície da carne utilizando um espectrofotômetro de refletância portátil da marca HunterLab, modelo MiniScan $®$ XE Plus. A escala de avaliação utilizada foi o CIE LAB, que consiste de três componentes de cores: L (indicação de luminosidade), a (indicação do teor de vermelho) e b (indicação do teor de amarelo).

A determinação do $\mathrm{pH}$ final foi realizada com eletrodo de penetração de corpo de vidro. O equipamento utilizado foi um potenciômetro de punção da marca Oakton, modelo pH 300, com compensação automática de temperatura.

Para a análise da perda de peso por gotejamento, dois cortes de aproximadamente $2,5 \mathrm{~cm}$ de espessura foram obtidos de cada amostra do músculo longissimus dorsi, que foram pesados, envoltos em embalagens plásticas reticuladas e suspensos no interior de sacos plásticos. O conjunto foi mantido em câmara fria à temperatura de $2 \pm 1^{\circ} \mathrm{C}$. Após 72 horas, procedeu-se a retirada das amostras para a realização da repesagem. A perda de peso por gotejamento foi expressa em porcentagem do peso final em relação ao peso inicial da amostra (Dirinck et al., 1996).

Todos os dados foram submetidos ao SAS LAB para verificação da adequação dos dados ao modelo linear. Posteriormente, realizaram-se as análises de variância dos dados de desempenho e qualidade da carne e de covariância dos dados de característica de carcaça pelo PROC GLM (General Linear Models) do SAS (Statistical Analysis System, 2001). A comparação de médias foi realizada pelo teste $\mathrm{F}$ a 5\% de significância.

\section{Resultados e Discussão}

A interação nível de ractopamina $\times$ nível de cromometionina não foi significativa $(\mathrm{P}>0,05)$ para nenhuma das variáveis de desempenho (Tabela 2). Não houve efeito significativo $(\mathrm{P}>0,05)$ da suplementação de ractopamina

Tabela 2 - Peso vivo inicial, peso vivo final, consumo diário de ração, ganho diário de peso e conversão alimentar dos animais

\begin{tabular}{|c|c|c|c|c|c|c|}
\hline Nível de ractopamina (ppm) & $\begin{array}{c}\text { Nível de } \\
\text { cromo-metionina } \\
(\mathrm{ppb})\end{array}$ & $\begin{array}{l}\text { Peso vivo } \\
\text { inicial } \\
(\mathrm{kg})\end{array}$ & $\begin{array}{l}\text { Peso vivo } \\
\text { final } \\
(\mathrm{kg})\end{array}$ & $\begin{array}{l}\text { Consumo } \\
\text { de ração } \\
(\mathrm{kg} / \mathrm{dia})\end{array}$ & $\begin{array}{l}\text { Ganho } \\
\text { de peso } \\
(\mathrm{kg} / \mathrm{dia})\end{array}$ & $\begin{array}{l}\text { Convesão } \\
\text { alimentar }\end{array}$ \\
\hline 0 & 0 & 26,56 & 112,88 & 2,57 & 0,947 & 2,72 \\
\hline \multirow[t]{2}{*}{5} & 0 & 26,60 & 115,49 & 2,64 & 0,976 & 2,64 \\
\hline & 400 & 26,64 & 116,16 & 2,52 & 0,982 & 2,57 \\
\hline \multicolumn{7}{|l|}{ Média dos fatores ${ }^{1}$} \\
\hline 0 & & 26,51 & 113,76 & 2,54 & 0,957 & $2,70 \mathrm{a}$ \\
\hline 5 & & 26,62 & 115,83 & 2,58 & 0,979 & $2,60 \mathrm{~b}$ \\
\hline \multicolumn{7}{|l|}{ Cromo-metionina } \\
\hline 0 & & 26,58 & 114,18 & $2,61 x$ & 0,961 & 2,68 \\
\hline 400 & & 26,55 & 115,41 & $2,51 \mathrm{y}$ & 0,975 & 2,63 \\
\hline Ractopamina $\times$ cromo-metionina $^{2}$ & & - & NS & NS & NS & NS \\
\hline
\end{tabular}


sobre o consumo diário de ração, resultado semelhante àqueles obtidos por vários pesquisadores que, também, não observaram qualquer efeito no consumo diário de ração dos animais em fases de terminação (Aalhus et al., 1990; Stites et al., 1991; Marinho et al., 2007). Esses resultados diferem, no entanto, daqueles relatados por Yen et al. (1990) e Mimbs et al. (2005), que observaram redução de, aproximadamente, $10 \%$ e $7 \%$ no consumo diário de ração dos animais, respectivamente.

De modo geral, a ractopamina tem proporcionado peso final superior (Weber et al., 2006; Xiong et al., 2006) e maiores ganhos diários de peso (Gu et al., 1991; Webster et al., 2001; Stoller et al., 2003). A administração de 5 ppm de ractopamina durante 28 dias pré-abate proporcionou aumento de $168 \mathrm{~g} /$ dia no ganho diário de peso, consequentemente, o peso de abate dos animais foi $4,68 \mathrm{~kg}$ maior, correspondendo a uma melhora de 3,78\% (Marinho et al., 2007). Neste estudo, porém, o mesmo não foi afetado $(\mathrm{P}>0,05)$ pela suplementação do referido agonista betaadrenérgico, bem como o ganho diário de peso dos animais $(\mathrm{P}>0,05)$.

Por outro lado, a suplementação de ractopamina proporcionou melhora $(\mathrm{P}=0,05)$ de aproximadamente $4 \%$ na conversão alimentar dos animais. Essa melhora está de acordo com os resultados obtidos por diversos estudos (Webster et al., 2001; Armstrong et al. 2004; Carr et al., 2005). A melhora na conversão alimentar pode estar relacionada ao direcionamento dos nutrientes para a deposição de tecido muscular, uma vez que a síntese de $1 \mathrm{~kg}$ de músculo requer menos energia que a síntese de $1 \mathrm{~kg}$ de gordura (Moser et al., 1986). Assim, sugere-se que suínos alimentados com ractopamina sejam mais eficientes na utilização dos nutrientes dietéticos (Marinho et al., 2007).

Constatou-se que a suplementação de cromo-metionina reduziu significativamente $(\mathrm{P}<0,03)$ o consumo diário de ração dos animais sem, contudo, influenciar a conversão alimentar $(\mathrm{P}>0,05)$ deles. Esses resultados concordam com os relatos de Page et al. (1993), que detectaram com a suplementação de 400 ppb e 800 ppb de picolinato de cromo diminuição no consumo diário de ração, sem afetar a conversão alimentar de suínos em crescimento e terminação. A redução no consumo diário de ração, encontrada no presente estudo, em dietas suplementadas com $400 \mathrm{ppb}$ de cromo-metionina, pode ser consequência do aumento da digestibilidade da matéria seca, ocasionando maior aproveitamento dos nutrientes dietéticos, conforme relataram Oliveira et al. (2007).

Não foi observado efeito significativo $(\mathrm{P}>0,05)$ da suplementação de cromo-metionina sobre o ganho diário de peso e a conversão alimentar para o período analisado, resultado semelhante àqueles obtidos por outros estudos com 200 ppb de picolinato de cromo, que, também, não relataram benefícios em ambas variáveis (Amoikon et al., 1995; Mooney \& Cromwell, 1999). Entretanto, diferentemente dos resultados apresentados em outras pesquisas, a suplementação de $200 \mathrm{ppb}$ de picolinato de cromo aumentou o ganho diário de peso (Lien et al., 2001) e melhorou a conversão alimentar (Lindemann et al., 1995).

Há evidências de que a suplementação de cromo é função da dose e do tempo de suplementação (Lindemann et al., 1995). Além disso, as variações nos resultados dos diversos estudos realizados podem ser decorrentes de diferenças no estado nutricional dos animais, tanto em termos de cromo como de outros nutrientes (Lima \& Guidoni, 1999). Assim, o grau de deficiência dos animais para tolerar a glicose pode determinar a amplitude da resposta (Mertz, 1993).

A interação nível de ractopamina $\times$ nível de cromometionina não foi significativa $(\mathrm{P}>0,05)$ para nenhuma das características de carcaça analisadas (Tabela 3 ). Houve efeito significativo $(\mathrm{P}=0,05)$ da adição de ractopamina sobre o rendimento de carcaça fria dos suínos. Algumas pesquisas anteriores, envolvendo suínos em crescimento e terminação (Brumm et al., 2004), ou em terminação (MarchantForde et al., 2003), mostraram que a inclusão de 10 ppm de ractopamina nas dietas não influenciou o rendimento de carcaça dos animais. Por outro lado, outros estudos desenvolvidos com 10 ppm de ractopamina na ração de terminação relataram aumento no rendimento de carcaça de suínos (Carr et al., 2005; Weber et al., 2006).

Maiores rendimentos de carcaça estão, na maioria das vezes, associados a animais com mais gordura, cujas carcaças poderão produzir ou apresentar menor porcentagem de porção comercializável ou comestível (Oliveira, 2005). A ractopamina e outras fenetanolaminas aumentam a porcentagem de carne (Mills, 2002), por serem substâncias capazes de aumentar a proporção de nutrientes depositados na carcaça em relação à deposição nos órgãos internos (Stahly \& Bark, 1991). Assim, pode-se deduzir que, no presente estudo, a deposição muscular da carcaça pode ter aumentado em uma proporção maior que o crescimento dos órgãos viscerais, de maneira que houve aumento do rendimento de carcaça fria nos suínos suplementados com ractopamina.

A suplementação de ractopamina influenciou $(\mathrm{P}<0,004)$ a área de olho-de-lombo, que apresentou aumento de, aproximadamente, $7 \%$ nos animais que receberam o referido agonista na dieta. A grande maioria das pesquisas, que avaliou a suplementação de ractopamina para suínos, obteve resultado favorável sobre a área de olho-de-lombo 
Tabela 3 - Rendimento de carcaça fria, comprimento de carcaça, espessura média de toucinho, área de olho-de-lombo e relação gordura:carne dos animais

\begin{tabular}{|c|c|c|c|c|c|c|}
\hline Nível de ractopamina (ppm) & $\begin{array}{l}\text { Nível } \\
\text { de cromo-metionina } \\
(\mathrm{ppb})\end{array}$ & $\begin{array}{c}\text { Rendimento } \\
\text { de carcaça } \\
(\%)\end{array}$ & $\begin{array}{l}\text { Comprimento } \\
\text { de carcaça } \\
(\mathrm{cm})\end{array}$ & $\begin{array}{c}\text { Espessura } \\
\text { média de } \\
\text { toucinho }(\mathrm{mm})\end{array}$ & $\begin{array}{c}\text { Área de } \\
\text { olho-de-lombo } \\
\left(\mathrm{cm}^{2}\right)\end{array}$ & $\begin{array}{l}\text { Relação } \\
\text { gordura: } \\
\text { carne }\end{array}$ \\
\hline 0 & $\begin{array}{c}0 \\
400\end{array}$ & $\begin{array}{l}77,59 \\
76,48\end{array}$ & $\begin{array}{l}99,40 \\
98,71\end{array}$ & $\begin{array}{l}23,20 \\
23,08\end{array}$ & $\begin{array}{l}46,85 \\
47,37\end{array}$ & $\begin{array}{l}0,36 \\
0,33\end{array}$ \\
\hline $\begin{array}{c}5 \\
\text { Média dos fatores } 1\end{array}$ & $\begin{array}{c}0 \\
400\end{array}$ & $\begin{array}{l}78,02 \\
77,68\end{array}$ & $\begin{array}{l}98,41 \\
97,58\end{array}$ & $\begin{array}{l}22,51 \\
21,92\end{array}$ & $\begin{array}{l}50,55 \\
50,08\end{array}$ & $\begin{array}{l}0,31 \\
0,30\end{array}$ \\
\hline $\begin{array}{c}\text { Cromo-metionina } \\
0 \\
400\end{array}$ & & $\begin{array}{l}77,80 \\
77,08\end{array}$ & $\begin{array}{l}98,90 \\
98,14\end{array}$ & $\begin{array}{l}22,86 \\
22,50\end{array}$ & $\begin{array}{l}48,70 \\
48,73\end{array}$ & $\begin{array}{l}0,34 \\
0,31\end{array}$ \\
\hline
\end{tabular}

(Stoller et al., 2003; Armstrong et al., 2004; Budiño et al., 2005; Weber et al., 2006; Xiong et al., 2006). O aumento da área de olho-de-lombo com a suplementação de 5 ppm de ractopamina pode ser consequência do aumento da síntese proteica no músculo esquelético e redução do catabolismo de aminoácidos. Essa hipótese encontra suporte em alguns trabalhos anteriormente desenvolvidos, nos quais suínos recebendo ractopamina, apresentaram concentrações menores de ureia plasmática (Dunshea et al., 1993; See et al., 2004).

Não houve efeito $(\mathrm{P}>0,05)$ da suplementação de ractopamina sobre a espessura de toucinho. Entretanto, há relatos mostrando que a ractopamina é capaz de reduzir essa variável (Crome et al., 1996; Mimbs et al., 2005; Pérez et al., 2006). Nas células adiposas, a mudança na resposta com períodos prolongados de utilização da ractopamina pode ser atribuída ao fenômeno conhecido como downregulation (Mills, 2002). Tal processo limita a efetividade dos receptores beta-adrenérgicos, reduzindo, no tecido adiposo, o número de receptores presentes na membrana celular para esse composto, em $28 \%$ em um dia e $53 \%$ em oito dias (Spurlock et al., 1994).

Embora a inclusão de 5 ppm de ractopamina nas dietas não tenha acarretado redução da espessura de toucinho $(\mathrm{P}>0,05)$, parâmetro importante na tipificação de carcaças suínas, foi observada melhora $(\mathrm{P}<0,04)$ de, aproximadamente, $12 \%$ na relação gordura:carne dos animais. Tal resposta está diretamente relacionada com o aumento da área de olho-de-lombo dos animais, evidenciando a capacidade da ractopamina proporcionar carcaças com maior quantidade de carne.
O presente estudo não mostrou qualquer efeito do cromo-metionina $(\mathrm{P}>0,05)$ nas características de carcaça dos suínos, contrariando os resultados de diversos estudos com picolinato de cromo (Page et al., 1993; Boleman et al., 1995; Lindemann et al., 1995; Lien et al., 2001). De maneira geral, tem-se relatado que o cromo pode potencializar a ação da insulina e, consequentemente, estimular o transporte ativo de glicose e aminoácidos para as células musculares, aumentando a síntese proteica (Mertz, 1993).

Não houve interação do nível de ractopamina $\times$ nível de cromo-metionina $(\mathrm{P}>0,05)$ para nenhuma das variáveis de qualidade da carne estudadas (Tabela 4). Por outro lado, constatou-se efeito da suplementação de 5 ppm de ractopamina nos teores de vermelho $(\mathrm{P}<0,004)$ e amarelo $(\mathrm{P}<0,05)$ e na perda de peso por gotejamento $(\mathrm{P}<0,05) \mathrm{da}$ carne dos animais. Esses resultados discordam daqueles obtidos por Uttaro et al. (1993), Carr et al. (2005) e Bridi et al. (2006), principalmente no que concerne à perda de peso por gotejamento. Enquanto neste estudo a inclusão de ractopamina nas dietas ocasionou diminuição na perda de peso por gotejamento, naqueles o referido agonista não acarretou alteração dessa variável.

Pesquisas anteriores também têm demonstrado reduções significativas da ractopamina sobre os teores de vermelho (Uttaro et al., 1993; Carr et al., 2005) e amarelo (Uttaro et al., 1993; Carr et al., 2005; Fernández-Dueñas et al., 2008). Essas respostas têm sido obtidas, ora com apenas 5 ppm e 7,4 ppm de ractopamina (Fernández-Dueñas et al., 2008), ora com 10 ppm e/ou 20 ppm (Uttaro et al., 1993; Carr et al., 2005). Entretanto, há relatos mostrando que a suplementação de 
Tabela 4 - Luminosidade, teor de vermelho, teor de amarelo, pH final e perda de peso por gotejamento do músculo longissimus dorsi

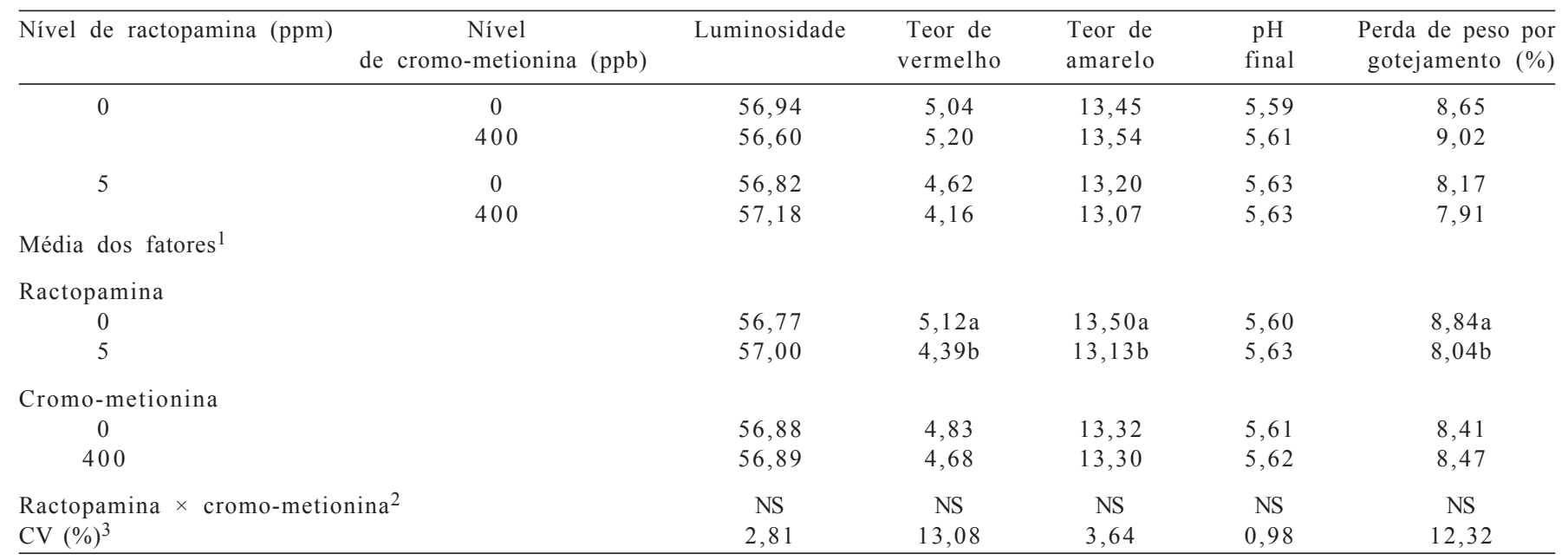

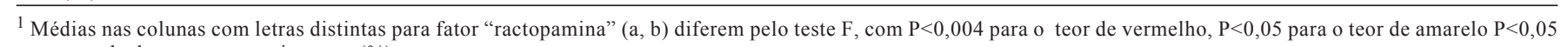
para perda de peso por gotejamento $(\%)$.

2 Não-significativo $(\mathrm{P}>0,05)$.

${ }^{3}$ Coeficiente de variação.

5, 10 ou 20 ppm de ractopamina para suínos não influenciou a coloração da carne (Stites et al., 1991; Crome et al., 1996; Armstrong et al., 2004). Além disso, neste estudo não foi observado efeito $(\mathrm{P}>0,05)$ nos valores de $\mathrm{L}$, resultado similar àqueles obtidos por outros pesquisadores (Armstrong et al., 2004; Bridi et al., 2006).

O teor de vermelho é indicativo da concentração de oximioglobina presente na carne (Uttaro et al., 1993). Assim, com o menor teor de vermelho encontrado neste estudo, pode-se sugerir que a inclusão de 5 ppm de ractopamina nas dietas de suínos reduziu a quantidade de mioglobina oxigenada na carne, tornando-a com coloração menos vermelha. Além disso, as alterações no teor de amarelo podem ser indicativo de mudanças na composição de ácidos graxos da gordura intramuscular (Joo et al., 2002).

Não houve efeito $(P>0,05)$ da suplementação de ractopamina sobre o $\mathrm{pH}$ final. Esse resultado é semelhante àquele obtido por Carr et al. (2005) e Bridi et al. (2006). A suplementação de salbutamol para suínos em fase de terminação ocasionou pH final mais elevado, sugerindo que os agonistas beta-adrenérgicos acarretaram menor produção de ácido lático na carcaça (Warriss et al., 1990).

A suplementação de cromo-metionina não influenciou $(\mathrm{P}>0,05)$ nenhuma das variáveis de qualidade da carne, resultado semelhante àqueles obtidos por outras pesquisas com picolinato de cromo que, também, não demonstraram qualquer efeito na qualidade da carne dos animais (Page et al., 1992; Boleman et al., 1995).

\section{Conclusões}

A inclusão de cromo-metionina na dieta de suínos em crescimento e terminação, apesar de reduzir o consumo diário de ração, não altera as características de carcaça nem a qualidade da carne dos animais. A ractopamina, no entanto, melhora o desempenho, as características de carcaça e a qualidade da carne dos suínos. A associação de ractopamina com cromo-metionina não é uma boa alternativa para melhoria do desempenho, das características de carcaça e, tampouco, da qualidade da carne dos animais.

\section{Referências}

AALHUS, J.L.; JONES, S.D.; SCHAEFER, S.D.M. et al. The effect of ractopamina on performance, carcass composition and meat quality of finishing pigs. Canadian Journal of Animal Science, v.70, n.5, p.943-952, 1990.

AMOIKON, E.K.; FERNANDEZ, J.M.; SOUTHERN, L.L. et al. Effects of chromium tripicolinate on growth, glucose tolerance, insulin sensitivity, plasma metabolites, and growth hormone in pigs. Journal of Animal Science, v.73, n.4, p.1123-1130, 1995.

ARMSTRONG, T.A.; IVERS, D.J.; WAGNER, J.R. et al. The effect of dietary ractopamina concentration and duration of feeding on growth performance, carcass characteristics, and meat quality of finishing pigs. Journal of Animal Science, v.82, n.11, p. 3245-3253, 2004.

ASSOCIAÇÃO BRASILEIRA DE CRIADORES DE SUÍNOS - ABCS. Método brasileiro de avaliação de carcaças. Estrela, 1973. 17p.

BOLEMAN, S.L.; BOLEMAN, S.J.; BIDNER, T.D. et al. Effect of chromium picolinato on growth, body composition, and tissue accretion in pigs. Journal of Animal Science, v.73, n.7, p.2033-2042, 1995.

BRIDI, A.M.; OLIVEIRA, A.R.; FONSECA, N.A.N. et al. Efeito do genótipo halotano, da ractopamina e do sexo do animal na qualidade da carne suína. Revista Brasileira de Zootecnia, v.35, n.5, p.2027-2033, 2006.

BRUMM, M.C.; MILLER, P.S.; THALER, R.C. Response of barrows to space allocation and ractopamina. Journal of Animal Science, v. 82, n.11, p.3373-3379, 2004.

BUDIÑO, F.E.L.; THOMAZ, M.C.; NEME, R. et al. Desempenho e características de carcaça de suínos em terminação recebendo diferentes níveis e marcas comerciais de cloridrato de ractopamina. Boletim de Indústria Animal, v.62, n.3, p.245-250, 2005. 
CARR, S.N.; RINCKER, P.J.; KILLEFER, J. et al. Effects of different cereal grains and ractopamina hydrochloride on performance, carcass characteristics, and fat quality in late-finishing pigs. Journal of Animal Science, v.83, n.1, p.223-230, 2005

CROME, P.K.; McKEITH, F.K.; CARR, T.R. et al. Effect of ractopamine on growth performance, carcass composition, and cutting yields of pigs slaughtered at 107 and 125 kilograms. Journal of Animal Science, v.74, n.4, p.709-716, 1996.

DIRINCK, P.; WINNE, A.; CASTEELS, M. et al. Studies on vitamin $\mathrm{E}$ and meat quality. 1. Effect of feeding high vitamin $\mathrm{E}$ levels on time-related pork quality. Journal of Agriculture and Food Chemistry, v.44, n.1, p.65-68, 1996.

DUNSHEA, F.R.; KING, R.H.; CAMPBELL, R.G. et al. Interrelationships between sex and ractopamine on protein and lipid deposition in rapidly growing pigs. Journal of Animal Science, v.71, n.11, p.2919-2930, 1993.

FERNÁNDEZ-DUEÑAS, D.M.; MYERS, A.J.; SCRAMLIN, S.M. et al. [2008] Carcass, meat quality, and sensory characteristics of heavy weight pigs fed ractopamina hydrochloride (Paylean ${ }^{\circledR}$ ). Journal of Animal Science, 2008. Abstract. Disponível em: $<$ http://jas.fass.org/cgi/content/abstract/jas.2008-0899v1> Acesso em: 27/9/2008.

GU, Y.; SCHINCKEL, A.P.; FORREST, J.C. et al. Effects of ractopamine, genotype, and growth phase on finishing performance and carcass value in swine: I. Growth performance and carcass merit. Journal of Animal Science, v.69, n.7, p.2685-2693, 1991.

JOO, S.T.; LEE, J.I.; HA, Y.L. et al. Effects of dietary conjugated linoleic acid on fatty acid composition, lipid oxidation, color, and water-holding capacity of pork loin. Journal of Animal Science, v.80, p.108-112, 2002.

LIEN, T.F.; WU, C.P.; WANG, B.J. et al. Effects of supplemental levels of chromium picolinate on the growth performance, serum traits, carcass characteristics and lipid metabolism of growingfinishing pigs. Animal Science, v.72, n.2, p.289-296, 2001.

LIMA, G.J.M.M.; GUIDONI, A.L. Níveis de cromo-ácido nicotínico em dietas de suínos em crescimento e terminação. Pesquisa Agropecuária Brasileira, v.34, n.3, p.433-439, 1999.

LINDEMANN, M.D.; WOOD, C.M.; HARPER, A.F. et al. Dietary chromium picolinate additions improve gain:feed and carcass characteristics in growing-finishing pigs and increase litter size in reproducing sows. Journal of Animal Science, v.73, n.2, p.457-465, 1995.

MARCHANT-FORDE, J.N.; LAY JR., D.C.; PAJOR, E.A. et al. The effects of ractopamina on the behavior and physiology of finishing pigs. Journal of Animal Science, v.81, n.2, p.416-422, 2003.

MARCHI, A. O consumo de carne suína no Brasil. In: CONFERENCIA INTERNACIONAL VIRTUAL SOBRE QUALIDADE DE CARNE SUÍNA, 2., 2001, Concórdia. Anais... Concórdia: EMBRAPA, 2001. p.29.

MARINHO, P.C.; FONTES, D.O.; SILVA, F.C.O. et al. Efeito da ractopamina e de métodos de formulação de dietas sobre o desempenho e as características de carcaça de suínos machos castrados em terminação. Revista Brasileira de Zootecnia, v.36, n.4, p.1061-1068, 2007.

McGRAW, D.; LigGeTt, S.B. Molecular mechanisms of $\hat{a}_{2}$ adrenergic receptor function and regulation. Proceedings of the American Thoracic Society, v.2, p.292-296, 2005.

MERTZ, W. Chromium in human nutrition: a review. Journal of Nutrition, v.123, n.4, p.626-633, 1993.

MILLS, S. Biological basis of the ractopamina response. Journal of Animal Science, v.80, supp1. 2, p.E28-E32, 2002.

MIMBS, K.J.; PRINGLE, T.D.; AZAIN, M.J. et al. Effects of ractopamine on performance and composition of pigs phenotypically sorted into fat and lean groups. Journal of Animal Science, v.83, n.6, p.1361-1369, 2005.

MITCHELL, A.D; SOLOMON, M.B.; STEELE, N.C. Influence of level of dietary protein or energy on effects of ractopamine in finishing swine. Journal of Animal Science, v.69, n.11, p.4487-4495, 1991

MOONEY, K.W.; CROMWELL, G.L. Efficacy of chromium picolinate on performance and tissue accretion in pigs with different lean gain potential. Journal of Animal Science, v.77, n.5, p.1188-1198, 1999

MOSER, R.L.; DALRYMPLE, R.H.; CORNELIUS, S.G. et al. Effect of cimaterol (CL 263, 780) as a repartitioning agent in the diet for finishing pigs. Journal of Animal Science, v.62, n.1, p.21-26, 1986

OLIVEIRA, A.L. Búfalos: produção, qualidade de carcaça e de carne Alguns aspectos quantitativos, qualitativos e nutricionais para promoção do melhoramento genético. Revista Brasileira de Reprodução Animal, v.29, n.2, p.122-134, 2005.

OLIVEIRA, V.; FIALHO, E.T.; LIMA, J.A.F. et al. Efeito do picolinato de cromo na digestibilidade dos nutrientes e metabólitos sanguíneos de suínos. Archivos de Zootecnia, v.56, n.214, p.137-143, 2007

PAGE, T.G.; BOLEMAN, S.L.; PIKE, M.M. et al. Effect of chromium picolinate on carcass traits and aging on pork quality. Journal of Animal Science, v.70, suppl. 1, p.218, 1992. (abst.)

PAGE, T.G.; SOUTHERN, L.L. WARD, T.L. et al. Effect of chromium picolinate on growth and serum and carcass traits of growing-finishing pigs. Journal of Animal Science, v.71, n.3, p.656-662, 1993.

PÉREZ, A.; OBISPO, N.E.; PALMA, J. et al. Efectos de la ractopamina y lisina sobre la deposición de grasa en cerdos seleccionados magros en la fase de engorda. Zootecnia Tropical, v.24, n.4, p.435-455, 2006.

SCHLINDWEIN, M.M; KASSOUF, A.L. Análise da influência de alguns fatores socioeconômicos e demográficos no consumo domiciliar de carnes no Brasil. Revista de Economia e Sociologia Rural, v.44, n.3, p.549-572, 2006.

SEE, M.T.; ARMSTRONG, T.A.; WELDON, W.C. Effect of a ractopamina feeding program on growth performance and carcass composition in finishing pigs. Journal of Animal Science, v.82, n. 8 , p.2474-2480, 2004

SPURLOCK, M.E.; CUSUMANO, J.C.; JI, S.Q. et al. The effect of ractopamina on â-adrenoceptor density and affinity in porcine adipose and skeletal muscle tissue. Journal of Animal Science, v.72, n.1, p.75-80, 1994.

STAHLY, T.S.; BARK, L.J. Impact of somatotropin and betaadrenergic agonists in swine. In: MILLER, E.R.; ULLREY, D.E.; LEWIS, A.J. (Eds.). Swine Nutrition. 1.ed. Stoneham, MA: Butterworth-Heinemann, 1991. p.103-117.

STATISTICAL ANALYSIS SYSTEM INSTITUTE - SAS. User's guide statistics. Cary, 2001. 155p.

STITES, C.R.; McKEITH, F.K.; SINGH, S.D. et al. The effect of ractopamina hydrochloride on the carcass cutting yields of finishing swine. Journal of Animal Science, v.69, n.8, p.3094-3101, 1991

STOLLER, G.M.; ZERBY, H.N.; MOELLER, S.J. et al. The effect of feeding ractopamina (Paylean) on muscle quality and sensory characteristics in three diverse genetic lines of swine. Journal of Animal Science, v.81, n.6, p.1508-1516, 2003

UTTARO, B.E.; BALL, R.O.; DICK, P. et al. Effect of ractopamine and sex on growth, carcass characteristics, processing yield, and meat quality characteristics of crossbred swine. Journal of Animal Science, v.71, n.9, p.2439-2449, 1993.

VICENT, J.B. The biochemistry of chromium. Journal of Nutrition, v.130, p.715-718, 2000.

WARRISS, P.D.; BROWN, S.N.; ROLPH, T.P. et al. Interactions between the beta-adrenergic agonist salbutamol and genotype on meat quality in pigs. Journal of Animal Science, v.68, n.11, p.3669-3676, 1990.

WEBER, T.E.; RICHERT, B.T.; BELURY, M.A. et al. Evaluation of the effects of dietary fat, conjugated linoleic acid, and 
ractopamine on growth performance, pork quality, and fatty acid prolifes genetically lean gilts. Journal of Animal Science, v.84, n.3, p.720-732, 2006.

WEBSTER, M.J.; GOODBAND, R.D.; TOKACH, M.D. et al. Interactive effects between Paylean ${ }^{\mathrm{TM}}$ (ractopamine $\mathrm{HCl}$ ) and dietary lysine on finishing pig growth performance, carcass characteristics and tissue accretion. Swine Day, p.77-85, 2001.
XIONG, Y.L.; GOWER, M.J.; LI, C.; ELMORE, C.A. et al. Effect of dietary ractopamina on tenderness and postmortem protein degradation of pork muscle. Meat Science, v.73, n.4, p.600$604,2006$.

YEN, J.T.; MERSMANN, H.J.; HILL, D.A. et al. Effects of ractopamina on genetically obese and lean pigs. Journal of Animal Science, v. 68, n.11, p.3705-3712, 1990. 